\title{
Prediction of Cutting Force and Tool Deflection in Micro Flat End Milling
}

\author{
Hye-Ri Gye, Byeong-Uk Song, Yong-Seok Lim, Yong-Wook Shin, Sung-Hui Jang, and Tae-Il Seo
}

\begin{abstract}
This paper presents an investigation of prediction of cutting force and tool deflection in micro flat end milling. To predict cutting forces specific cutting force coefficients KT and KR were used. In fact, various cutting forces prediction models were proposed in past researches for conventional sized machining processes. However, micro end-milling processes were known as different phenomenon as respect to macro end-milling. Many past researches concerned complicated different models for micro end-milling from macro end-milling. However, cutting force models for both macro and micro end milling were fundamentally based on measured cutting forces for a series of experimental machining processes. Then, cutting force model proposed by Tlusty, which was developed for macro end-milling, was applied for micro flat end milling because this model is relatively simple. Finite element method was used to predict tool deflection based on predicted cutting forces. Predicted tool deflection amounts and actual machined profiles were compared each other in order to check out the differences between them.
\end{abstract}

Index Terms-Cutting force, micro end-mill, finite element method, tool deflection.

\section{INTRODUCTION}

Recently ultra-precision micro patterns and shapes are widely used in a number of industrial fields [1]. Various processes based on semi-conductor processing techniques are used in fabrication of micro shapes and patterns, however mechanical cutting method has lately attracted considerable attention because of various available materials, flexibility of process and high-productivity. The main purpose of this study strongly concerned cutting force prediction processes for micro machining. In fact, various cutting forces prediction models were proposed in past researches for conventional sized machining processes [2]-[4]. However, micro end-milling processes were known as different phenomenon as respect to macro end-milling. Many past researches concerned complicated different models for micro end-milling from macro end-milling [5]-[7]. However, cutting force models for both macro and micro end milling were fundamentally based on measured cutting forces for a series of experimental machining processes. Then, in this paper cutting force model proposed by Tlusty [2] and Lee [4] which was developed for macro end-milling, was applied for micro end milling because this model is relatively simple. This model will be installed platform system which can be

Manuscript received November 5, 2012; revised January 20, 2013.

The authors are with the Major of Mechanical Engineering and Robotics in Division of Mechanical System Engineering at the University of Incheon, Incheon 406-772 Korea (e-mail: \{ghr0114, mempisto, iys1987, yonggal1101, jsh2375, tiseo\} @incheon.ac.kr). accessed by various users. To verify experimental micro flat end-milling processes were carried out and the composed results were presented in this paper.

\section{Cutting Force Prediction Model}

There were many researches about phenomenon of conventional end-milling using macro scale cutting tools. However it is difficult to apply these researches to micro end-milling processes because micro end mill size is quietly smaller than macro scale end mills. For this minimum chip thickness effect was studied by considering more significant size of tool tip nose radius than macro tools [5]-[6]. If micro end-milling phenomenon would be observed in a microscopic view point, the minimum chip thickness maybe certainly considered. In fact, cutting force prediction model was on the basis of a series of experimental works because it is very difficult to analytically estimate a relationship between a tool and a material, as known by tool-matter couple. Therefore, if resultant forces were predicted by measured cutting forces, it would be possible to apply the cutting force prediction model for macro scale end-milling to micro end-milling processes. In this paper a cutting force prediction model was applied as follows, which was developed on the basis of Tlusty [2] and Lee models [4]. When $S_{t}$ is feedrate per tooth and $\Phi$ is engaged angle, chip thickness $h$ can be depicted by Eq. 1 .

$$
\begin{gathered}
h=S_{t} \sin \Phi \text { for down milling } \\
h=S_{t} \sin \left(\Phi+\Phi_{1}\right) \text { for up milling }
\end{gathered}
$$

Fig. 1 shows in cutting force components and geometric relationships of up and down milling. Considering instantaneous tangential and radial cutting force components $K_{T}$ and $K_{R}$, tangential cutting force component $F_{t}$ and radial cutting force component $F_{r}$ can be depicted by (2).

$$
F_{T}=K_{T} b h \text { and } F_{R}=K_{R} b h
$$

If $\gamma$ is radius of cutting tool and $\beta$ is helix angle of tool, $d z$ can be depicted by (3).

$$
d_{Z}=\frac{\gamma}{\tan \beta} d \Phi
$$

The X-directional infinitesimal cutting force $d F_{X}$ and Y-directional infinitesimal cutting force $d F_{Y}$ can be arranged as (4) for down milling and (5) for up milling by (1)-(4). 


$$
\begin{gathered}
d F_{X}=\left\{-\frac{K_{T} S_{t} \gamma}{\tan \beta} \sin ^{2} \Phi+\frac{K_{R} S_{t} \gamma}{\tan \beta} \sin \Phi \cos \Phi\right\} d \Phi \\
d F_{X}=\left\{-\frac{K_{T} S_{t} \gamma}{\tan \beta} \sin \Phi \cos \Phi-\frac{K_{R} S_{t} \gamma}{\tan \beta} \sin ^{2} \Phi\right\} d \Phi \\
d F_{X}=\frac{K_{T} S_{t} \gamma}{\tan \beta} \sin ^{2}\left(\Phi+\Phi_{1}\right) d \Phi \\
-\frac{K_{R} S_{t} \gamma}{\tan \beta} \sin \left(\Phi+\Phi_{1}\right) \cos \left(\Phi+\Phi_{1}\right) d \Phi \\
d F_{Y}=\frac{K_{T} S_{t} \gamma}{\tan \beta} \sin \left(\Phi+\Phi_{1}\right) \cos \left(\Phi+\Phi_{1}\right) d \Phi \\
+\frac{K_{R} S_{t} \gamma}{\tan \beta} \sin ^{2}\left(\Phi+\Phi_{1}\right) d \Phi
\end{gathered}
$$

Therefore $d F_{X}$ and $d F_{Y}$ can be integrated according to different cutting regions as shown in Fig. 1. This cutting force model could be completed by experimentally measured cutting forces.

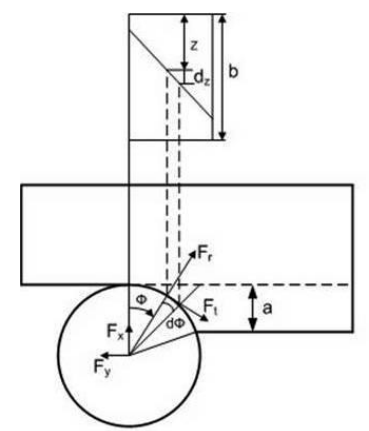

(a) Up milling

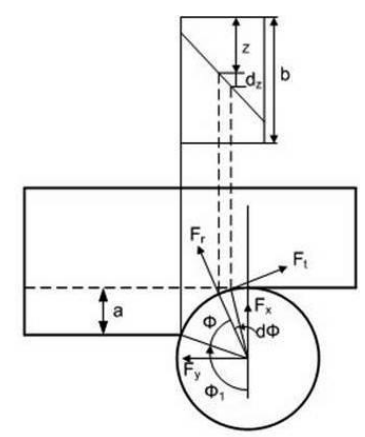

(b) Down milling (a) Cutting force components for up and down milling

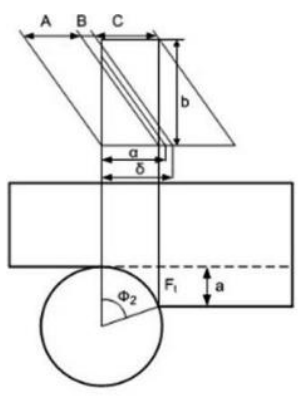

(a) Up milling

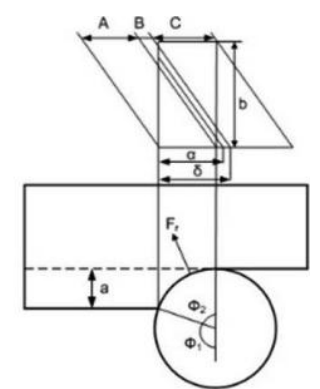

(b) Down milling (b) Contact length of cutting edge at cutting position.

Fig. 1. Cutting force components and Contact length of cutting edge.

\section{EXPERIMENTAL WORKS}

\section{A. Micro End-Milling System}

For experimental works of micro end-milling process, a micro machining stage was established as shown in Fig. 2, which has 3-axis of degree of freedom (X-, Y-, Z-axis) and can be controlled in sub-micro unit and the control resolution is $0.1 \mu \mathrm{m}$. A high speed spindle was used in experimental works. This spindle consists of air-bearings, AC Motor and an inverter, which can rotate until 100,000rpm. The air-bearing make the spindle cannot generate sufficient torque when tool diameter is relatively large; however the air-bearing allows rotating in high speed and micro end-milling do not need large torque for cutting when using micro end-mills. For more information about the micro machining system was depicted in Table I.

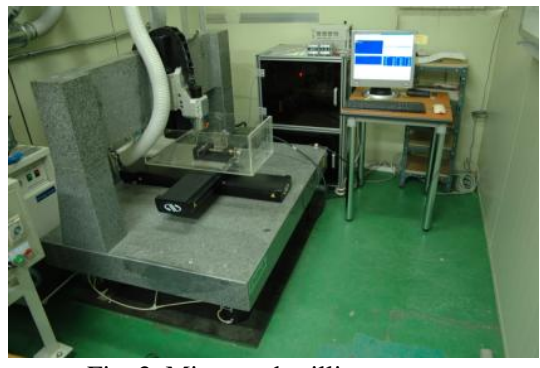

Fig. 2. Micro end-milling system.

TABLE I: SYSTEM SPECIFICATION

\begin{tabular}{ll}
\hline \hline Traveling range & X, Y-axis : 600mm, Z-axis : 200mm \\
\hline Resolution & X, Y, Z-axis : $0.1 \mu \mathrm{m}$ \\
\hline Accuracy & X, Y-axis : $0.2 \mu \mathrm{m}$ \\
\hline Repeatability & X, Y, Z-axis : $0.2 \mu \mathrm{m}$ \\
\hline Max. velocity & X, Y-axis : $200 \mathrm{~mm} / \mathrm{sec}$, Z-axis : 100mm $/ \mathrm{sec}$ \\
\hline Rotational speed & Max. 100,000rpm \\
\hline Spindle run-out & Max. 0.6 $\mu \mathrm{m}$ \\
\hline Static radial load & Min. 6kgf \\
\hline Workpiece weight & Max. 45kgf \\
\hline Lubrication & Dry cutting \\
\hline \hline
\end{tabular}

\section{B. Experimental Conditions}

In experimental works two end-mills were mainly used. The end-mills of $1 \mathrm{~mm}$ diameter were used for roughing and the end-mills of $0.3 \mathrm{~mm}$ diameter were used for finishing of micro end-milling. The study concerned micro end-milling. Table II shows other experimental conditions and Fig. 3 shows schematic of experimental works.

TABLE II: CUTTING EXPERIMENTAL CONDITIONS

\begin{tabular}{ll}
\hline \hline Micro cutting mode & Side cutting \\
\hline Feedrate $(\mathrm{mm} / \mathrm{min})$ & 300 \\
\hline Axial depth of cut $(\mu \mathrm{m})$ & 350 \\
\hline Radial depth of cut $(\mu \mathrm{m})$ & $100,150,200(130,170)$ \\
\hline Tool & $300 \mu \mathrm{m}$ \\
\hline Workpiece & 2 -flute flat end-mill \\
\hline Cutting speed(RPM) & Brass \\
\hline Cutting mode & 40,000 \\
\hline
\end{tabular}

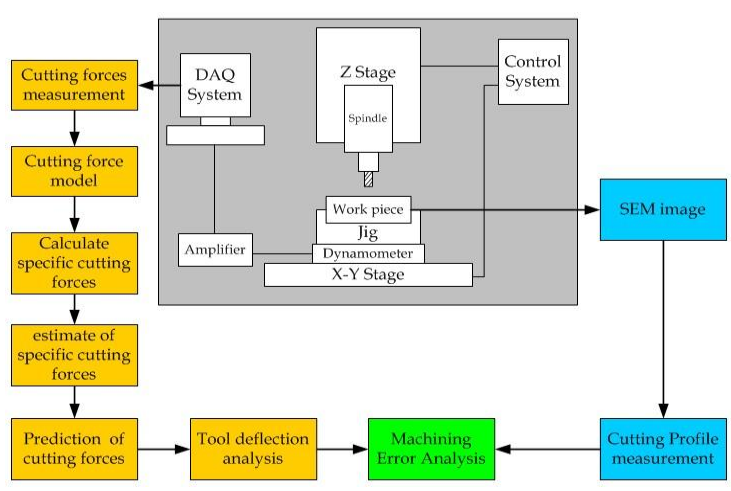

Fig. 3. Experimental system schema. 


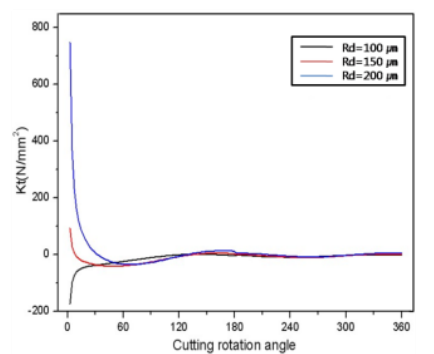

(a) $\mathrm{K}_{\mathrm{T}}$ when $\mathrm{Rd}=100,150$ and $200 \mu \mathrm{m}$

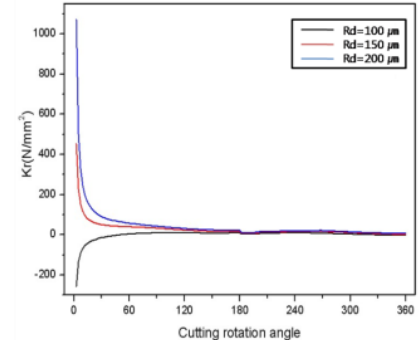

(b) $\mathrm{K}_{\mathrm{R}}$ when $\mathrm{Rd}=100,150$ and $200 \mu \mathrm{m}$
Fig. 4. Measured $\mathrm{K}_{\mathrm{T}}$ and $\mathrm{K}_{\mathrm{R}}$

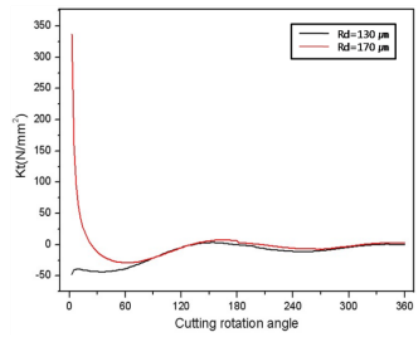

(a) $\mathrm{K}_{\mathrm{T}}$ when $\mathrm{Rd}=130$ and $170 \mu \mathrm{m}$

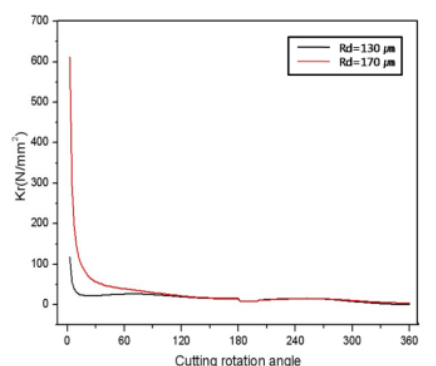

(b) $K_{R}$ when $\mathrm{Rd}=130$ and $170 \mu \mathrm{m}$
Fig. 5. Predicted $K_{T}$ and $K_{R}$

\section{Cutting Force Prediction}

For cutting force prediction Tlusty model and Lee model were derived by instantaneous tangential and radial cutting force components, $\mathrm{K}_{\mathrm{T}}$ and $\mathrm{K}_{\mathrm{R}}$, which can be determined by measured cutting forces through a series of actual machining tests under given certain cutting conditions. Therefore it is possible to predict discrete cutting forces as well as resultant cutting forces from measured resultant forces. However as mentioned above, it is obvious that there are differences between machining process phenomena using macro-scaled and micro-scaled tools. If cutting force prediction models were obtained by measured resultant cutting forces, it can be unnecessary to take into account an entire phenomenon of micro-scaled machining processes in a microscopic view point. Therefore in this paper the cutting force model was used, which was derived for macro-scaled machining processes.

\section{Experimental Results}

For cutting force prediction, resultant cutting forces were measured at every $2.4^{\circ}$ of tool rotation and instantaneous tangential and radial cutting force components, $\mathrm{K}_{\mathrm{T}}$ and $\mathrm{K}_{\mathrm{R}}$, were calculated by the cutting force prediction model on the basis of measured cutting forces. Fig. 4 shows calculated values of $K_{T}$ and $K_{R}$, when radial depth of cut was $100 \mu \mathrm{m}$, $150 \mu \mathrm{m}$ and $200 \mu \mathrm{m}$.

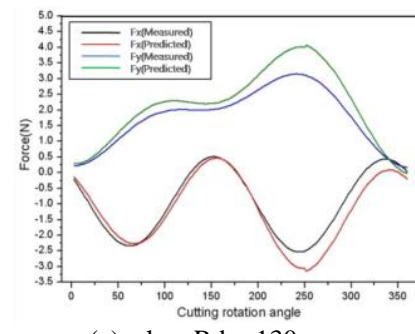

(a) when $\mathrm{Rd}=130 \mu \mathrm{m}$

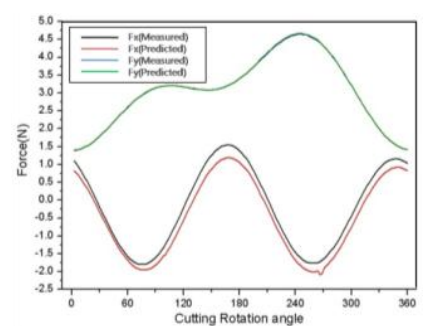

(b) when $\mathrm{Rd}=170 \mu \mathrm{m}$
Fig. 6. Comparison between predicted and measured forces.

On the basis of values of $\mathrm{K}_{\mathrm{T}}$ and $\mathrm{K}_{\mathrm{R}}$ calculated from measured cutting forces, it was possible to predict values of $\mathrm{K}_{\mathrm{T}}$ and $\mathrm{K}_{\mathrm{R}}$ which were not measured and calculated. Fig. 5 shows predicted values of $K_{T}$ and $K_{R}$, when radial depth of cut was $130 \mu \mathrm{m}$ and $170 \mu \mathrm{m}$. The cutting forces could be predicted by the cutting force prediction model on the basis of predicted values of $\mathrm{K}_{\mathrm{T}}$ and $\mathrm{K}_{\mathrm{R}}$. To verify predicted cutting forces, other machining tests were carried out. Fig. 6 shows predicted and measured cutting forces when radial depth of cut was $130 \mu \mathrm{m}$ and $170 \mu \mathrm{m}$. Good agreements between predicted and measured cutting forces appear on experimental results.

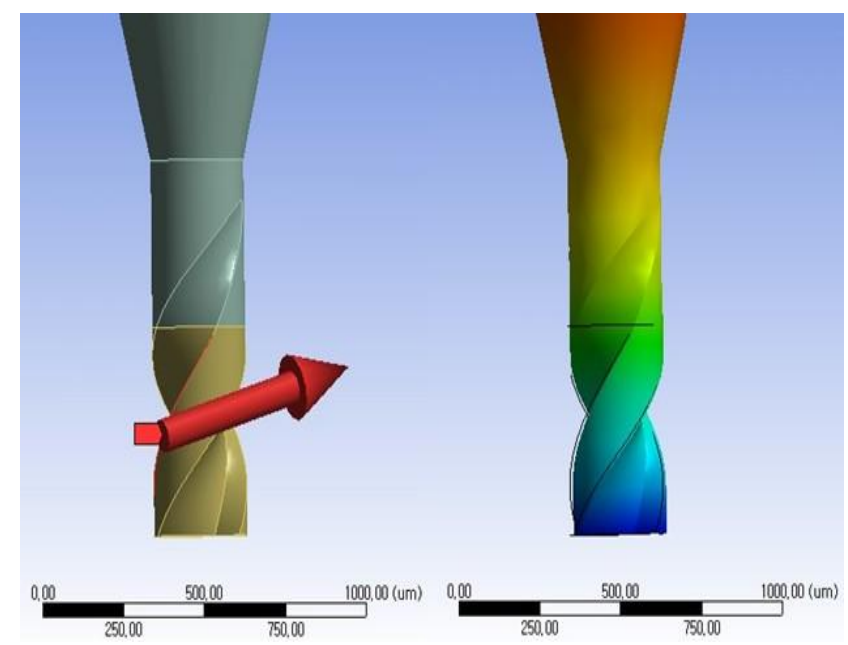

Fig. 7. Graphic results of FEM analysis.

\section{FEM ANALYSIS OF TOOL DEFLECTION}

To estimate micro tool deflection amounts, a FEM (Finite Element Method) approach was used with ANSYS WorkBench. Considering predicted cutting forces it was possible to also predict micro tool deflection amounts as shown in Fig. 7. In fact deflected cutting shapes do not exactly correspond upon actual machined profiles because cutting forces vary according to tool rotation. However if this kind of investigation would be tried according, it can be expected that this analysis would help to predict machining errors caused by excessive cutting forces during machining processes. This is very important because the machining errors strongly affect the machining quality.

\section{CONCLUSIONS}

This paper presents a process of cutting force prediction for micro-scaled machining through a model which was originally derived for macro-scaled machining. It is because that excessive cutting forces can cause tool deflection, and then significant machining errors can appear. In this paper, cutting force models for both macro and micro end milling were fundamentally based on measured cutting forces for a series of experimental machining processes. Then, cutting force model proposed by Tlusty and Lee for macro end-milling was applied for micro end milling in this paper because this model is relatively simple. To verify proposed 
approach, experimental works were carried out and it was possible to predict the cutting forces with good agreements as respect to measured cutting forces. Moreover a Finite Element Analysis was conducted to predict tool deflection. It can be expected that this process can help to improve the quality of micro end-milling processes.

\section{ACKNOWLEDGMENT}

This work was supported by Research Grant of University of Incheon.

\section{REFERENCES}

[1] F. Z. Fang, K. Liu, T. R. Kurfess, and G. C. Lim, MEMS/NEMS Handbook, 2006.

[2] J. Tlusty and P. Macneil, "Dynamics of cutting forces in end milling," Annals of the CIRP, vol. 24, no. 1, pp. 21-25, 1975.

[3] W. A. Kline, R. E. DeVor, and J. R. Lindberg, "The prediction of cutting forces in end milling with application to cornering cut," International Journal of Machine Tool Design and Research, vol. 22, no. 1, pp. 7-22, 1982.

[4] Y. M. Lee, S. H. Lee, W. I Tae, O. J. Kwon, and B. H. Choi, "Cutting force variation of inconel 718 in up and down end milling with different helix angles," Journal of the Korean Society of Precision Engineering, vol. 18, no. 7, pp. 143-148, July 2001.

[5] W. Y. Bao and I. N. Tansel, "Modeling micro-end-milling operations. Part I: Analytical cutting force model," International Journal of Machine Tool and Manufacture, vol. 40, pp. 2155-2173, 2000.

[6] Vogler $\mathrm{el} \mathrm{al,} \mathrm{"On} \mathrm{the} \mathrm{modeling} \mathrm{and} \mathrm{analysis} \mathrm{of} \mathrm{machining} \mathrm{performance}$ in micro end-milling, Part $\Pi$ : Cutting force prediction," Journal of Manufacturing Science and Engineering, vol. 126, pp. 695-705, 2004

[7] J. Chae, S. S. Park, and T. Freiheit, "Investigation of micro-cutting operations," International Journal of Machine Tool and Manufacture, vol. 46, pp. 313-332, 2006.

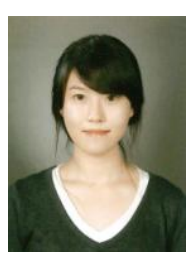

Hye-Ri Gye is a master degree pre-candidate of Major of Mechanical Engineering and Robotics in Division of Mechanical System Engineering at the University of Incheon in Korea. Her research interests included micro machining, injection mold technology, optimal design, Flow Analysis for injection molds, medical instrument design and so on. Currently her research is related to methodology to improve the quality of spray system for living products. Kye received her bachelor degree of Mechanical Engineering from the University of Incheon in Korea in 2012.

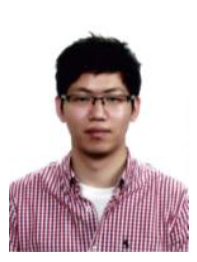

Byeong-Uk Song is a Ph.D. pre-candidate of Major of Mechanical Engineering and Robotics in Division of Mechanical System Engineering at the University of Incheon in Korea. His research interests included micro machining, micro mold technology, optimal design, Finite Element Analysis for injection molds, medical instrument design and so on. Currently his research is related to methodology to improve the quality of micro machining processes assisted by ultrasonic vibration. Song received his master degree in precision micro machining processes from the University of Incheon in Korea in 2012.

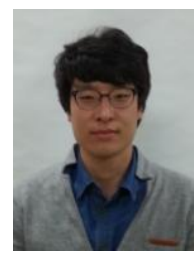

Yong-Seok Lim is a master degree pre-candidate of Major of Mechanical Engineering and Robotics in Division of Mechanical System Engineering at the University of Incheon in Korea. His research interests included micro machining, micro mold technology, optimal design, Finite Element Analysis for injection molds, medical instrument design and so on. Currently his research is related to methodology to improve the quality of micro machining processes assisted by ultrasonic vibration. Lim received his bachelor degree of Mechanical Engineering from the University of Incheon in Korea in 2012.

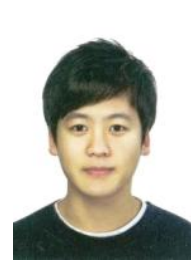

Yong-Wook Shin is a bachelor degree pre-candidate of Major of Mechanical Engineering and Robotics in Division of Mechanical System Engineering at the University of Incheon in Korea. His research interests included 3-D Modeling, Rapid Prototyping, Reverse Engineering, Optimal Design, Injection Mold Design and so on. Currently his research is related to Optimal design of injection molds. Shin will be in master degree course in precision micro machining processes from the University of Incheon in Korea in 2012.

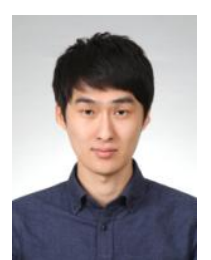

Sung-Hui Jang is a bachelor degree pre-candidate of Major of Mechanical Engineering and Robotics in Division of Mechanical System Engineering at the University of Incheon in Korea. His research interests included 3-D Modeling, Rapid Prototyping, Reverse Engineering, Optimal Design, Injection Mold Design and so on. Currently his research is related to Optimal design of injection molds. Jang will be in master degree course in precision micro machining processes from the University of Incheon in Korea in 2012.

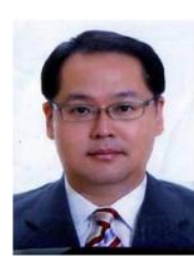

Tae-Il Seo is a professor of major of mechanical engineering and robotics in Division of Mechanical System Engineering at the University of Incheon in Korea. $\mathrm{He}$ is also a director of RICT (Regiona Innovation Center of Technology) of the University of Incheon. Seo received his bachelor degree of Mechanical Engineering in 1989, his master degree of Robotics in 1993 from the University of Inha in Korea and his Ph.D of Mechanical Engineering from Ecole Centrale de Nantes in France in 1998. He has been a senior researcher of Precision Mold Team in KITECH (Korea Institute of Industrial Technology) in Korea (1998-2003). Since 2003 he has been Assistant Professor (2003-2006) and Associate Professor (2007-2012) at the University of Incheon. His research interests included micro machining, micro mold technology, optimal design, Finite Element Analysis for injection molds, medical instrument design and so on. Currently his research is related to methodology to improve the quality of micro machining processes assisted by ultrasonic vibration. 